\title{
Art Education and Sensitive Tolos Innovation Project in the Training of Early Childhood Education Teachers
}

\author{
Inés López-Manrique \\ University of Oviedo, Oviedo, Asturias, Spain
}

\begin{abstract}
This paper shows the experience developed in the compulsory subject Expression Laboratory of the 4th year of the Early Childhood Education Teaching Degree at the University of Oviedo within the Innovation Project Art Education and Sensitive Tools for Early Childhood Education (PINN-20-A-056). An optional project that was developed online during the first term of 2020-2021. It was developed in a stressful situation for the students, an educational context of distance learning, in which they felt stress and pandemic fatigue (COVID-19), with the additional disadvantage of not having common physical spaces in which to develop the artistic work of the subject in a context of didactics for Early Childhood Education. The objective was to integrate activities related to sensory stimuli and the well-being of people through the Visual Arts. To this end, a group of $\mathrm{N}=115$ pupils were given the tools of art therapy and other disciplines. With a qualitative methodology, through semi-structured interviews, activities and questionnaires, the results were measured. The results are considered to have been positive, with an increase in motivation towards Art Education subjects. In conclusion, Art Therapy, Music Therapy and Mindfulness generate moments of relaxation and reduce anxiety in students.
\end{abstract}

Keywords---art education, art therapy, COVID-19, innovation project, mindfulness, music therapy.

\section{Introduction}

The situation generated by the pandemic (COVID-19) in all areas has given rise to different experiences, many of them related to Education and New Technologies (Yefimenko et al., 2021). The calls for Educational Innovation Projects have supported these experiences, as is the case of the University of Oviedo project presented below (PINN-20-A-056). This project has tried to alleviate the stress of students during classes, which has facilitated a greater motivation towards them

Linguistics and Culture Review (c) 2021.

Corresponding author: Manrique, I. L.-; Email: lopezines@uniovi.es

Manuscript submitted: 18 July 2021, Manuscript revised: 27 Oct 2021, Accepted for publication: 09 Nov 2021

794 
and a sense of wellbeing in the students. In this case, it was carried out in a subject that integrates Art Education, a unique challenge as there was no workshop to work in person both individually and in groups (Aykac, 2015; Stes et al., 2010). With screen-based communication, the students' sense of hyperconnectedness was enhanced by a program of simple activities that worked the five senses and introduced students to Art Therapy, Music Therapy and Mindfulness (Betts, 2006; Gantt \& Tinnin, 2009). The theoretical framework of the project is presented below, followed by the qualitative method and results. The results have been divided into two sections according to the two defined moments of the project. Finally, the discussion and conclusions are provided.

\section{Theoretical framework of the project}

The subject Expression Laboratory is taught in the fourth year of the Bachelor's Degree in Early Childhood Education during the first four-month period and is compulsory (Muzyka et al., 2021). It integrates contents related to Plastic Expression, Corporal Expression and Musical Expression. Around 120 students are gathered in two groups dedicated to theoretical aspects and five groups to Laboratory Practices. During this time, several teachers give classes in standard classrooms and in spaces with specific materials such as the Gymnasium, the Music Classroom and the Plastic Arts Classroom of the Faculty of Teacher Training and Education.

During the 2019-2020 and 2020-2021 academic years, the pandemic (COVID-19) has generated changes in all activities, including education. This has also had an impact on the way in which this subject of a markedly experiential nature and with a high number of students is taught (Mantra et al., 2016; Kanca et al., 2020). The use of new technologies and distance learning have been imposed for the first time. But as a first term subject it was not affected in 2020 as it was taught before the compulsory quarantine in many countries during the first months of 2020. Nor did it suffer from the impetus of the impromptu telematics teaching that followed and raised the stress levels of both students and their teachers (Anderson et al., 2020).

Currently in Higher Education, this mode of teaching is the dominant one, while according to Oña-Simbaña (2020), at other educational levels it is also combined with other more face-to-face formulas, such as in Pre-school Education, but there is a general saturation of exposure to screens among minors (Lacave et al., 2020). It has been during the current academic year that this adaptation to distance learning has been necessary, just at a time when both pupils and society in general are beginning to show the first symptoms of pandemic fatigue.

We said that the subject is made up of three parts and the last one taught is the one related to Art Education, coinciding with the end of the semester and the handing in of work, with the first exams coming up soon. In other words, a time of high workload and stress. This was one of the reasons for generating a project that would integrate activities related to Art Therapy, relaxation and sound as a positive reinforcement in the teaching of the Bachelor's Degree in Early Childhood Education. 
The project contemplates the possibility of optionally integrating individual activities in order to encourage the use of these tools with students at a later date. Art Therapy is used in health contexts as a healing tool within a therapeutic process in which more techniques and instruments are involved. Several authors (Conejo \& Chinchilla, 2010; Ajamil, 2018; Marxen, 2011; Vanegas Farfano et al., 2017), have also worked with it in educational contexts, obtaining beneficial results in dynamics, families, cases of stress, people with schizophrenia, etc.

Both artistic activities and Art Therapy encourage work with the senses and the recognition of sensory characteristics in materials and the environment. Encouraging this kind of sensory awareness is particularly positive for the training of early childhood education teachers and a line of work that has been followed by different visual and plastic artists since the 1960s.

We mentioned that Art Therapy has grown in recent years in experiences and research within educational, social and health contexts. As well as sister disciplines such as Music Therapy, a working tool that also offers benefits to people of all ages (Wigram \& Lawrence, 2005; Yasuhara \& Sugiyama, 2001). Its beneficial application in special education and health settings such as hospitals has been demonstrated by Ortega et al. (2009), who observed reduced anxiety, increased levels of communication and social interaction, improved emotional development and greater psychological, physical and emotional balance.

In university students, Curl (2008), found a reduction in stress when they carried out a programme of cognitive artistic activity during times when they were experiencing stressful personal situations. Also within this same educational level, Eaton \& Tieber (2017), demonstrated positive effects such as the reduction of anxiety with the practice of colouring activities.

Different actions are being considered to combat the level of anxiety and stress that this global pandemic process is generating in students. Datlen \& Pandolfi (2020), have applied a virtual art therapy programmed with adults who have learning difficulties due to the impossibility of holding face-to-face sessions, observing that it has facilitated communication, inclusion and connection among its members.

Similarly Gatto et al. (2020), have concluded that, in an adult population with social isolation due to confinement, Art Therapy and Augmented and Virtual Reality Mindfulness methods provided psychological well-being. In turn, Malboeuf-Hurtubise et al. (2020), have analyzed the impact of the pandemic on children's mental health, pointing out that previous research has demonstrated the benefits of art-based therapies and for this reason work should be done along these lines. To this end, they have carried out interventions with drawing and the practice of drawing mandalas in the primary school population, demonstrating beneficial results and a decrease in levels of hyperactivity.

The aforementioned initiatives of a therapeutic nature reinforce the proposal of this innovation project. During this academic year, an intervention was carried out in the group, with the actions being located in the area of Plastic Expression. Moreover, it is important to remember that Plastic and Visual Expression in the 
Degree in Early Childhood Education Teacher Training provides an experiential teaching and a flexible methodological approach different from that of other subjects, which is allowed by the nature of the subject. In the same way, the project is intended to be developed according to experts in the area who agree on the categorization of three types of activities, which in turn become three ways of approaching the sensory. These are actions of analysis, appreciation and finally expression (Suryasa, 2019).

\section{Methods}

\section{Work plan developed and methodology}

The methodology is qualitative, the work plan of the Visual Arts and Sensitive Tools for Early Childhood Education project was divided into three main phases as follows (Table 1.). The programmed activities were carried out over three weeks with an approximate duration of thirty-five minutes per week and group. These included Art Therapy actions that included body expression, synesthesia, breathing-relaxation, guided drawing and the use of sound and drawing from images. During that month, at the end of the sessions, semi-structured interviews of a non-compulsory nature were carried out, to which slightly more than half of the students replied.

Table 1

Work plan phases

\begin{tabular}{lll}
\hline Phases & $\begin{array}{l}\text { Development of the 2020-21 } \\
\text { academic year }\end{array}$ & Activities \\
\hline Phase I & September-October & $\begin{array}{l}\text { Organization of project } \\
\text { sessions, definition of } \\
\text { activities and } \\
\text { methodology. }\end{array}$ \\
Phase II & October & $\begin{array}{l}\text { Creation of development } \\
\text { materials and } \\
\text { measurement scales. }\end{array}$ \\
Phase III & November-December & $\begin{array}{l}\text { Implementation and } \\
\text { assessment }\end{array}$ \\
\hline
\end{tabular}

During the months of September and October, the bibliography related to the purposes of the project was reviewed. The sequence of activities was also organized, as well as the materials needed for each one of them, trying to keep in line with the contents to be dealt with in the subject. Then, in October, the materials were finalized and the instruments for measuring and assessing the project by the students were created.

As the subject is divided into sequences according to the subject to be tackled, during November and December the block corresponding to Art Education was taught. 


\section{Participants and measurement instruments}

The number of students who participated was $\mathrm{N}=115$, of which $95 \%$ were female. The ages ranged from 20 to 39 years. Measuring instruments were used to measure ranges and levels.

Table 2

Assessment of indicators no. indicator mode of assessment ranks set and achieved

\begin{tabular}{|c|c|c|c|}
\hline No. & Indicator & Mode of assessment & $\begin{array}{l}\text { Ranks set and } \\
\text { achieved }\end{array}$ \\
\hline 1 & $\begin{array}{l}\text { Final project of the } \\
\text { course }\end{array}$ & $\begin{array}{l}\text { Submission of the final } \\
\text { project of the course. }\end{array}$ & $\begin{array}{l}\text { Qualitative } \\
\text { assessment and } \\
\text { subsequent } \\
\text { quantification. } \\
\text { (Fail, Pass, Good, } \\
\text { Excellent, Merit) }\end{array}$ \\
\hline 2 & $\begin{array}{l}\text { Semi-structured } \\
\text { interview }\end{array}$ & $\begin{array}{l}\text { Semi-structured } \\
\text { interviews (including } \\
\text { student satisfaction with } \\
\text { the project). }\end{array}$ & $\begin{array}{l}\text { Qualitative } \\
\text { assessment and } \\
\text { subsequent } \\
\text { quantification. }\end{array}$ \\
\hline 3 & Part "A" Questionnaire & $\begin{array}{l}\text { Questionnaire designed } \\
\text { ad hoc with a closed } \\
\text { response (including the } \\
\text { degree of satisfaction of } \\
\text { the students with the } \\
\text { project). }\end{array}$ & $\begin{array}{l}\text { Ranges from 1-5 rated } \\
\text { with percentages. } \\
\text { (5-Very high, 4-High, } \\
\text { 3-Medium, 2- Low } \\
\text { and 1-Very low). }\end{array}$ \\
\hline 4 & $\begin{array}{l}\text { Part "B" } \\
\text { Questionnaire }\end{array}$ & $\begin{array}{l}\text { Ad hoc open-ended } \\
\text { questionnaire. }\end{array}$ & $\begin{array}{l}\text { Qualitative } \\
\text { assessment }\end{array}$ \\
\hline
\end{tabular}

\section{Results}

\section{First results}

Some initial results were deduced from the interviews. The sample consisted of $\mathrm{N}=65$ students of the Bachelor's Degree in Early Childhood Education, 95\% were female. The first results were positive, an increase in motivation towards the subject was observed. In the implementation phase $85 \%$ of the cases used expressions such as "the activities relax me", 70\% considered them fun and 60\% thought that they should be integrated regularly in the classes. The answers to open questions have positive responses. Regarding Question 1: How was the experience developed? Why? The following type of answers were received (examples 1-5). 
1) "Pleasant".

2) "In general I really enjoy drawing and painting, it relaxes me, and doing it with music has been a positive complement to the experience".

3) "It was nice and easy, because by letting yourself go through something already guided and unstructured, it made me feel less worried about the end".

4) "It has been very pleasant, depending on the sound I listened to, it led me to imagine a different situation, on a sheet of paper I drew rain and clouds, a feeling of a storm. On another sheet of paper I drew a field that gave the sensation of a lot of wind and the grass was going from one side to the other and I heard bells and I also drew them".

5) "It was nice and easy, but it is true that it was strange to do an activity like this with the kind of teaching we are having this year (I liked it and I wish there were more like this)".

"With regard to Question 2: Do you think that this type of activity can be taught in Early Childhood Education? Different comments were obtained, exemplified in the following lines (examples 6-10)".

6) "I think that we can work on Art Education (aspects of colour, lines, materials...), Musical Expression (following a rhythm, listening, coordinating motor skills with the sound we are listening to...), attention, concentration and relaxation".

7) "Many things can be taught, apart from plastic contents such as the line or the dot, the importance of creativity, emotions, knowing how to relax, being patient, etc., is given".

8) "With this type of activities, we can work on the contents of plastic arts, for example with Abstract Expressionism, several activities can be done to bring the children closer to this type of painting".

9) "Creativity, artistic skills, musical content (different authors, well-known works) can be encouraged. We can relax and thus consciously get to know our own emotions, letting them out and doing so, drawing them on paper, letting go and at the same time relaxing, etc. I think that these are very enriching activities, especially in a pre-school environment, which is usually an environment where children live fast, there is a lot of commotion and silence is conspicuous by its absence. The control of emotions and knowing how to listen to them (emotional intelligence) is something that should be worked on from childhood to avoid possible mental illnesses in the future. With music playing in the background while we do these activities, we can also imagine things, evoke places and feelings while we work".

10) "It was easy and relaxing, I liked it".

Finally, the standard answers to Question 3 (examples 11-16) are indicated.

11) "Question 3 focused on asking about the benefit obtained by developing these practices in Early Childhood Education, most of the answers are in line with the examples".

12) "I think it is interesting because we work on aspects of plastic and musical expression in the same activity".

13) "Yes, because it develops creativity and helps them to escape from reality". 
14) "They are dynamic activities that allow the children to participate, they work in a playful way and it's very entertaining".

15) "Yes, I think that developing this type of activity is beneficial for children in early childhood education as it helps the development of motor skills and the development of perception of what they see, hear and/or feel".

16) "It is an activity that allows them to have a moment of calm, to listen to themselves, to let go a little of what is inside them and also to encourage their creativity".

\section{Final results}

The largest number of participants belonged to the second theoretical group TB (PL3, PL4, PL5) which represented $62.5 \%$ of the total (Figure 1).

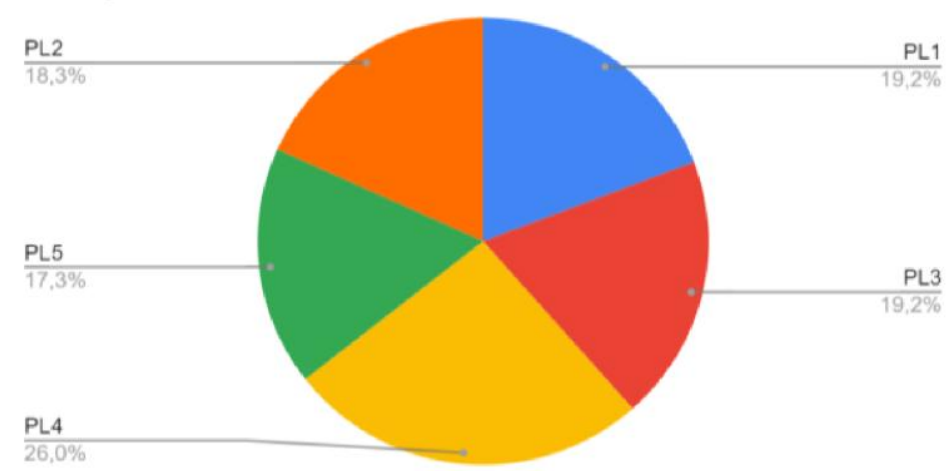

Figure 1. Groups involved in the project

A specific questionnaire of open (part "A") and closed (part "B") questions for the assessment of the project was created and answered by 104 students (Table 6 and Table 7). Questions were also included to provide specific information about the project in relation to the subject.

Table 6

Perception the Art Therapy activities and related tools

\begin{tabular}{l}
$\begin{array}{l}\text { The internships I have done } \\
\text { have helped me to disconnect } \\
\text { and relax. }\end{array}$ \\
$\begin{array}{l}\text { They highlight the Art Therapy } \\
\text { activities and related tools that } \\
\text { they have included in their } \\
\text { final work. }\end{array}$ \\
$\begin{array}{l}\text { With the activities carried out } \\
\text { in the course I have learnt new } \\
\text { resources to facilitate a state of } \\
\text { relaxation. }\end{array}$ \\
\hline
\end{tabular}


Table 7

Application of the activities of the subject and specific art therapy and related tools in the final works of the subject

\begin{tabular}{|c|c|}
\hline $\begin{array}{l}\text { It highlights the teaching } \\
\text { resources they have included } \\
\text { in their final work. }\end{array}$ & $76,9 \%$ \\
\hline $\begin{array}{l}\text { It highlights the Art Therapy } \\
\text { activities and related tools that } \\
\text { they have included in their } \\
\text { final work. }\end{array}$ & $54,85 \%$ \\
\hline $\begin{array}{l}\text { He/She considers that with the } \\
\text { activities carried out in the } \\
\text { subject he has learnt new } \\
\text { artistic techniques. }\end{array}$ & $71,2 \%$ \\
\hline $\begin{array}{l}\text { He thinks that with the } \\
\text { activities carried out in the } \\
\text { subject you have learnt about } \\
\text { new artists and artistic } \\
\text { movements. }\end{array}$ & $60,6 \%$ \\
\hline
\end{tabular}

\section{Assessment of indicators}

Given that research carried out in different fields of education has observed an improvement in the internal variables of the person thanks to the work with art therapies, it is expected to observe a positive response to these actions in the students. Surveys designed ad hoc were carried out, applied after the work placement and at the end of the course, in which different aspects were evaluated. The introduction of this subject in the course is a novelty, which is expected to be reflected in the final projects of the course in which the students carry out their approaches, so they are also considered as an indicator.

\section{Key observations on the experience}

After carrying out the activities, the semi-structured interviews were conducted. At that time, the assessment of the project was very positive. The practice developed seems to be more beneficial on the day of the class itself than afterwards. Trying to apply these issues in their final coursework seems to be relatively easy and very necessary as explained in the semi-structured interviews, but they do not consider them very prominent in their final work.

The results have been more positive while the project was being developed than after some time had passed and the project had been closed. So it seems that these actions are necessary during the learning and teaching process, but it is difficult to apply them afterwards due to the limitations of the digital world are necessary during the learning and teaching process, but it is difficult to apply them later due to the limitations of the digital world. 
It is observed that there are relationships between the personal values obtained and the proposals developed.

\section{Discussion}

As mentioned at the beginning of the Innovation Project, the main objective was to give the possibility during small periods of time within the subject to provide Art Therapy tools and sensory resources to students who, in these times of pandemic, suffer stress and are hyper connected to digital devices (Barrios et al., 2016; de Melo et al., 2020). In this way, and through Visual and Plastic Expression, they will be able to connect with a more "sensitive and tangible" reality and also in this way collaborate in their training as teachers of the Degree in Early Childhood Education.

As Curl (2008), Eaton \& Tieber (2017), have shown, certain artistic programmes and activities favour the reduction of anxiety. In this case the students stated that this was the case after the exercises, although this was not assessed with specific validated questionnaires but with semi-structured interviews. In the Innovation Project it has been observed that it is possible to integrate notions of Art Therapy, Music Therapy and Mindfulness favouring moments of relaxation for the students (Mrazek et al., 2019; Baer, 2019). It would be interesting to be able to measure which type of activity and modality is more beneficial. In general, a positive assessment of the project was observed from the students, who in some cases considered this type of work outside the digital world to be surprising but beneficial.

Anderson et al. (2020), showed that teachers and students had experienced anxiety and stress during the period of confinement in the spring of 2020. During 2021, the situation is becoming more protracted and such initiatives seem to be necessary as programmes to reduce stress caused by the pandemic through artistic practice are being implemented in different places and levels of education around the world (Datlen \& Pandolfi, 2020; Gatto et al., 2020; MalboeufHurtubise et al., 2020).

Actions of the three types recommended in the area of Visual and Plastic Expression have been carried out. The analysis actions have served as an introductory basis together with the appreciation actions and finally the expression actions have been the basis of the work as the latter have helped them to relax and connect more with themselves and their corporeality. Although the Microsoft Teams platform and the YouTube channel have been used as a "plastic arts classroom", it has been possible to carry out all three types of activities. However, later on, when the students got together on the platform channels to put questions in common, it seems that the digital supports were not sufficient for the development of collaborative work.

It is important to point out that obstacles have been overcome, but obviously the same conditions have not been achieved as in a physical classroom. In cases such as working with drawing and painting in activities in which feelings and sounds are interpreted or working with gestural resources such as Dripping in Expressionist Painting, another context is more beneficial. The restriction of space 
is obvious, as is the limitation of time. In this sense, placing this experience at another time of the course or in other subjects is a possible way of development.

\section{Conclusions}

Undoubtedly, the difference in results between the time of the project and the end of the project raises the question of whether there are other ways for the students not to forget the positive effects of the activities. If they were to integrate them into their normal routines and contribute to their well-being, the project's objectives would be greatly enhanced. But for this it would be necessary to follow up and perhaps intervene from other areas of knowledge more expert in working with the psychological aspects of students. Even so, it can be said that small oases have been created where feeling and relaxing were more important than attending to a screen and a didactic exhibition. This is absolutely natural in childhood, but is relegated later on.

\section{Author contributions}

ILM has completely realized the project and drafted for this article with all the actions that this entails

\section{Competing interests}

There are no conflicting interests.

\section{Grant information}

The author declared that no grants were involved in supporting this work.

\section{Acknowledgements}

We would like to thank all the students of the Degree in Early Childhood Education who have participated in the project and the Centre for Teaching Innovation of the University of Oviedo, which has accepted this project in its call for Teaching Innovation Projects 2020-2021.

\section{References}

Ajamil, E. G. (2018). Propuesta de un modelo teórico de intervención en arteterapia familiar. El proceso creativo como herramienta terapéutica en el trabajo con familias. Arteterapia, 13, 137.

Anderson, R. M., Heesterbeek, H., Klinkenberg, D., \& Hollingsworth, T. D. (2020). How will country-based mitigation measures influence the course of the COVID-19 epidemic? The lancet, 395(10228), 931-934.

Aykac, V. (2015). An application regarding the availability of mind maps in visual art education based on active learning method. Procedia-Social and Behavioral Sciences, 174, 1859-1866. https://doi.org/10.1016/j.sbspro.2015.01.848

Baer, R. (2019). Assessment of mindfulness by self-report. Current opinion in psychology, 28, 42-48. https://doi.org/10.1016/j.copsyc.2018.10.015

Barrios, E., López-Gutiérrez, A., \& Lechuga, C. (2016). Facing challenges in English Medium Instruction through engaging in an innovation project. Procedia-Social and Behavioral Sciences, 228, 209-214. https://doi.org/10.1016/j.sbspro.2016.07.031 
Betts, D. J. (2006). Art therapy assessments and rating instruments: Do they measure up?. The Arts in psychotherapy, 33(5), 422-434. https://doi.org/10.1016/j.aip.2006.08.001

Conejo, I. M. G., \& Chinchilla, M. D. C. (2010). ¿ Puede la terapia artística servir a la educación?. EA, Escuela abierta, 13, 69-95.

Curl, K. (2008). Assessing stress reduction as a function of artistic creation and cognitive focus. Art Therapy, 25(4), 164-169.

Datlen, G. W., \& Pandolfi, C. (2020). Developing an online art therapy group for learning disabled young adults using WhatsApp. International Journal of Art Therapy, 25(4), 192-201.

de Melo, J. C. F., Salerno, M. S., Freitas, J. S., Bagno, R. B., \& Brasil, V. C. (2020). From open innovation projects to open innovation project management capabilities: A process-based approach. International Journal of Project Management, 38(5), https://doi.org/10.1016/j.ijproman.2020.06.006

Eaton, J., \& Tieber, C. (2017). The effects of coloring on anxiety, mood, and perseverance. Art Therapy, 34(1), 42-46.

Gantt, L., \& Tinnin, L. W. (2009). Support for a neurobiological view of trauma with implications for art therapy. The Arts in Psychotherapy, 36(3), 148-153. https://doi.org/10.1016/j.aip.2008.12.005

Gatto, C., D’Errico, G., Nuccetelli, F., De Luca, V., Paladini, G. I., \& De Paolis, L. T. (2020, September). XR-Based Mindfulness and Art Therapy: Facing the Psychological Impact of Covid-19 Emergency. In International Conference on Augmented Reality, Virtual Reality and Computer Graphics (pp. 147-155). Springer, Cham.

Kanca, I. N., Ginaya, G., \& Sri Astuti, N. N. (2020). The effectiveness of the problem solving method on learning outcomes of the English course for room division operation during the COVID-19 pandemic. International Journal of Linguistics, Literature and Culture, $7(1), \quad 12-22$. https://doi.org/10.21744/ijllc.v7n1.1102

Lacave, T. T., Barrio, T. V., Álvarez, R. S. Á. S., \& Martínez, L. M. F. (2020). El papel de los padres en el comportamiento online de menores hiperconectados. Revista Latina de Comunicación Social, (75), 121-148.

Malboeuf-Hurtubise, C., Léger-Goodes, T., Mageau, G. A., Taylor, G., Herba, C. M., Chadi, N., \& Lefrançois, D. (2021). Online art therapy in elementary schools during COVID-19: results from a randomized cluster pilot and feasibility study and impact on mental health. Child and Adolescent Psychiatry and Mental Health, 15(1), 1-11.

Mantra, I. B. N., Kusuma, I. N. W., Suarka, I. N., \& Putra, I. B. R. (2016). Exploring the educational values of oral texts of balinese oral tradition. International Journal of Linguistics, Literature and Culture, 2(2), 141146.

Marxen, E. (2011). Diálogos entre arte y terapia: del arte psicótico al desarrollo de la arteterapia y sus aplicaciones. Diálogos entre arte y terapia, 1-222.

Mrazek, A. J., Mrazek, M. D., Cherolini, C. M., Cloughesy, J. N., Cynman, D. J., Gougis, L. J., ... \& Schooler, J. W. (2019). The future of mindfulness training is digital, and the future is now. Current Opinion in Psychology, 28, 81-86. https://doi.org/10.1016/j.copsyc.2018.11.012 
Muzyka, O., Lopatiuk, Y., Belinska, T., Belozerskaya, A., \& Shvets, I. (2021). Modern aesthetic education and its further directions. Linguistics and Culture Review, 5(S4), 12-21. https://doi.org/10.21744/lingcure.v5nS4.1537

Oña-Simbaña, J. M. (2020). Desafios de la educación preescolar en tiempos de COVID-19. CienciAmérica, 9(2), 138-145.

Ortega, E., García, L. E., Estévez, A. F., \& Cánovas, D. A. (2009). Aplicaciones de la musicoterapia en educación especial y en los hospitales. European Journal of Education and Psychology, 2(2), 145-168.

Stes, A., Min-Leliveld, M., Gijbels, D., \& Van Petegem, P. (2010). The impact of instructional development in higher education: The state-of-the-art of the research. Educational research review, 5(1), 25-49. https:/ / doi.org/10.1016/j.edurev.2009.07.001

Suryasa, W. (2019). Historical Religion Dynamics: Phenomenon in Bali Island. Journal of Advanced Research in Dynamical and Control Systems, 11(6), 1679-1685.

Vanegas Farfano, M., González Ramírez, M. T., \& Landero Hernández, R. (2017). Un modelo estructural sobre la reducción del estrés utilizando material artístico. Arteterapia. Papeles de arteterapia y educación para inclusión social, 12, 79-94.

Wigram, T., \& Lawrence, M. (2005). Music therapy as a tool for assessing hand use and communicativeness in children with Rett Syndrome. Brain and Development, 27, S95-S96. https://doi.org/10.1016/j.braindev.2005.03.019

Yasuhara, A., \& Sugiyama, Y. (2001). Music therapy for children with Rett syndrome. Brain and Development, 23, S82-S84. https://doi.org/10.1016/S0387-7604(01)00336-9

Yefimenko, I. V., Yakymchuk, O. M., Kravtsova, N. Y., Sotska, H. I., \& Korol, A. M. (2021). Art education development in the context of global changes. Linguistics and Culture Review, 5(S2), 501-513. https://doi.org/10.21744/lingcure.v5nS2.1386 